University of Wollongong

Research Online

Faculty of Business - Papers (Archive)

Faculty of Business and Law

January 2015

Talking yourself into work: insights from sociolinguistics about gender and the employment interview

Mary Barrett

University of Wollongong, mbarrett@uow.edu.au

Follow this and additional works at: https://ro.uow.edu.au/buspapers

Research Online is the open access institutional repository for the University of Wollongong. For further information contact the UOW Library: research-pubs@uow.edu.au 


\title{
Talking yourself into work: insights from sociolinguistics about gender and the employment interview
}

\begin{abstract}
This chapter gives a brief critical history of three phases of linguistic research into gender and language: an essentialist phase, a constructionist phase and a post-structuralist phase. It pays particular attention to the post-structuralist phase, which focuses on how meaning is actively constructed by both parties to a speech event such as a conversation, and the consequences of particular judgements by the more powerful participants, especially in 'gate-keeping' conversations such as job interviews. We pay particular attention to research into naturally occurring conversations, which employs conversation analysis (CA), an interactional sociolinguistics technique. Campbell and Roberts's (2007) CAbased study of intercultural employment interviews yielded complex, detailed understandings about how candidates' speech led to favourable or unfavourable assessments of them during the employment interview. In this chapter we reanalyse Campbell and Roberts's data from a gender perspective and find that some aspects of what is often stereotypically considered 'women's language' - aspects that conflict with the 'rules' of interview performance - are likely to lead to unfavourable assessments of women as potential employees. This strongly suggests that some types of interview interaction that are normative for women, for example, high levels of frankness, high levels of personal disclosure and narrativized speech, are likely to act to women's disadvantage when they attempt to 'get in' to organizations. The chapter concludes with a summary of the implications of the re-analysis for women's entry into the world of paid work, including suggestions about how interviewees and interviewers can overcome these unfavourable and unfounded judgements.
\end{abstract}

\section{Keywords}

about, gender, employment, interview, sociolinguistics, insights, into, work, talking, yourself

\section{Publication Details}

Barrett, M. (2015). Talking yourself into work: insights from sociolinguistics about gender and the employment interview. In A. Broadbridge \& S. Fielden (Eds.), Handbook of Gendered Careers in Management: Getting In, Getting On, Getting Out (pp. 105-122). Cheltenham (UK): Edward Elgar Publishing. 


\title{
Chapter 7
}

\section{Talking yourself into work: Insights from sociolinguistics about gender and the employment interview}

\author{
Mary Barrett
}

This chapter gives a brief critical history of three phases of linguistic research into gender and language, an essentialist phase, a constructionist phase and a post-structuralist phase. It pays particular attention to the post-structuralist phase, which focuses on how meaning is actively constructed by both parties to a speech event such as a conversation, and the consequences of particular judgements by the more powerful participants, especially in 'gate-keeping' conversations such as job interviews. We pay particular attention to research focused on naturally occurring conversations using conversation analysis (CA), an interactional sociolinguistics technique. CA yields complex, detailed understandings about how a candidate's speech leads to favourable or unfavourable assessments of them during the employment interview. Campbell and Roberts' (2007) study that examined intercultural employment interviews is re-analysed from a gender perspective. The re-analysis finds that some aspects of what is often stereotypically considered 'women's language' - aspects which conflict with the 'rules' of interview performance - are likely to lead to unfavourable assessments of women as potential employees. This strongly suggests that some types of interview interaction which are normative for women, e.g. high levels of frankness, high levels of personal disclosure and narrativized speech, are likely to act to women's disadvantage when they attempt to 'get in' to organizations. The chapter concludes with a summary of the implications of the re-analysis for women's entry into the world of paid work, including suggestions about how interviewees and interviewers can overcome these unfavourable and unfounded judgements. 


\section{Research into gender and language: three phases}

The history of academic research into language and gender can be seen as forming three phases: an essentialist phase, a constructionist phase and a post-structuralist phase.

\section{The essentialist paradigm}

The early stages of academic linguistic interest in women's speech style, in the 1970s and 1980s, saw women's speech styles theorized in one of three ways: as inferior to that of men (e.g. Lakoff, 1973), dominated by that of men (e.g. Spender, 1980; Zimmerman and West, 1975) or as different from but equal to that of men (e.g. Coates, 1993; Hirschman, 1973; Holmes, 1995; Tannen, 1990; 1994; 1996; 1999). Tannen, whose work bridges popular literature and academic research, exemplifies the 'difference' perspective. She argues that men and women use language in contrasting ways which stem from their different conceptualizations of the world and their goals within it. For example, Tannen (1990) says that for men, the world is a competitive place in which conversation and speech are used to build status and demonstrate independence, whereas for women the world is a network of connections, so they use language to seek and offer support and intimacy. Men seek solutions to problems, leading them to give advice, whereas women seek comfort and sympathy for their problems. These contrasts are echoed in men's preference for conversation oriented to obtaining information and women's orientation to conversation about feelings, men's preference for direct imperatives and women's preference for super-polite forms, men's greater ease with conflict and women's avoidance of conflict in favour of compromise.

Researchers within the essentialist perspective differ about whether women's speech styles should be changed to emulate the more powerful and authoritative speech styles of men. However, as Cameron (1995) points out, citing etiquette manuals from the fifteenth century, the view that women are naturally and properly quiet has a long history. So it is not 
surprising that essentialist theorists are united in regarding certain aspects of speech as the direct outcome of the speaker's gender, and seeing men's speech as reliably different from women's speech. Essentialist studies produced catalogues of gender-related speech differences, e.g. gender-linked differences in vocabulary, interruption, talk time, topic initiation and topic maintenance. Despite criticisms of this research, e.g. for reinforcing gender dualism (Hollway, 1994), perpetuating gender stereotypes (Crawford, 1995), and producing a research culture that exaggerates sex differences (Hare-Mustin and Maracek, 1994), studies that search for and discuss evidence of gendered conversational styles continue to be published (e.g. Conrick, 1999; Goddard and Patterson, 2000; Mapstone, 1998).

\section{The constructionist paradigm}

In the 1990s, research into language and gender shifted towards a constructionist viewpoint, theorizing gender as a complex and fluid social property located in the interaction between speakers (e.g. Bohan, 1993; Bucholtz, Liang and Sutton, 1999; Butler, 1990; Crawford,1995; West and Fenstermaker, 1993; Wodak, 1997). This research perspective draws attention to how gender is naturalized in common usage by analysing written and visual tests including radio broadcasts, advertisements, newspaper articles and CCTV footage, noting the similarities and differences between languages and speech communities in how they encode and express sexism. The feminist language reform movement (cf. Pauwels, 1998), which aims to change the biased representation of the sexes in language whereby men are portrayed as the norm, is part of this approach. However since some constructionist research continues to treat gender as an independent variable, exploring how men 'do' masculinity, and women 'do' femininity, but not the reverse (Cameron, 1998; Stokoe, 2000), it has been argued to reinstate the essentialist frameworks it aimed to replace (e.g. Cameron 1998; Stokoe, 2000). 
Poststructuralist perspectives have also had an impact in gender and language research, particularly for analysing and interpreting discourses. Following Foucault (1972, p. 49), we define discourses here as 'practices that systematically form the objects of which they speak'. Discourses are 'forms of knowledge, sets of assumptions, expectations, values and ways of explaining the world that govern mainstream cultural practices' (Baxter, 2006, p. 156). Poststructuralist perspectives point to essentialist views that assume that the genders are different as a dominant discourse, that is, the essentialist viewpoint constitutes rather than reveals reality. The idea that women and men are different in how they communicate is a staple not only of recent bestsellers on the subject (e.g. Gray, 1992; Tannen, 1990; 1994), but also of much language and gender research literature. Three other features of poststructuralist approaches are important in this context. First, poststructuralist approaches exemplify a stance of incredulity towards meta-narratives (Lyotard, 1984, p. xxiv), i.e. they avoid sweeping theorizations about causes and effects in favour of locating, describing and analysing small-scale, localized and temporary settings. Second, poststructuralist perspectives exemplify a belief in the multiplicity of human identity. People's identity comprises a complex and sometimes contradictory mix of gender, age, class, ethnicity, education, language, personality, and so on. Finally, the idea of 'identity in process' is important. Within any single speech event, male and female speakers constantly negotiate their subject positions within interwoven and often competing or contradictory institutional discourses.

Interactional sociolinguistics and poststructural approaches to language and gender

Interactional sociolinguistics, through the technique of $\mathrm{CA}$, is allied to poststructural perspectives in foregrounding what Schegloff, one of CA's original practitioners and proponents, referred to as 'the problem of relevance' (Schegloff, 1991, p. 49). Even though 
gender linguistically permeates everything that is encoded, said and implied, poststructuralist perspectives show how other factors - a speaker's ethnicity, education, age, workplace role, the conversation's institutional context - are also encoded in a person's talk. Since we can characterize people and speech events in so many different ways, the question arises: which one is the right one, for analytical purposes? CA identifies how, in natural speech situations, speakers frame these factors as relevant when they are talking to others.

The alliance between CA and poststructuralism has not been unproblematic. Some feminist researchers with a poststructuralist orientation, for example, regard Schegloff's requirement that speakers in an interaction explicitly invoke gender as 'unbearably limiting' (e.g. Kitzinger, 2000) for research with a political agenda such as feminism. More recently, however, Schegloff himself (e.g. Schegloff, 1997) and some feminist researchers, for example, Stokoe, 2000 and Speer, 2005) have advocated widening CA techniques to allow analysts' perspectives on an issue to be included even when speakers do not explicitly make the issue relevant. This is particularly important especially when the topic being discussed is already problematized.

\section{Characteristics of CA conversation analysis research}

Conversations range from the casual, 'socializing' event of two friends chatting on the phone to conversations we intuitively recognize as aimed at accomplishing other things: discussing a prognosis with a doctor, reporting an emergency, giving a witness statement, getting married. All entail myriad aspects of what Sacks (1984) refers to as 'the technology of conversation': pacing, silences, assessments, turn-taking systems, mechanisms for indicating what is salient in the conversation, and so on. CA determines how these technologies accomplish the 'actions' which differentiate types of conversation. An important insights of early CA practitioners is that the sequential location of an utterance (which can include 
pauses, intakes of breath, the extent and frequency of overlaps and so on), is crucial to creating its practical meaning. This can be seen in the following example from an analysis of a medical consultation:

Patient: This- chemotherapy (0.2) it won't have any effects on havin' kids, will it?

Doctor: (2.2)

Patient: It will?

Doctor: I'm afraid so. Source: Frankel (1984, p. 153), cited in ten Have (1999, p. 33).

Notes for interpreting symbols in CA transcripts:

- One or more colons indicate the expansion of the previous sound, e.g. Tha::t.

- A '?' marks upward intonation characteristic of a question.

- Underlining indicates stress placed on a word or part of a word.

- $\quad$ Extended brackets mark overlap between speakers [ ].

- Numbers in parentheses e.g. (0.2) indicate pauses in tenths of a second; (.) indicates a micropause.

- An equals sign = indicates the absence of a discernible gap between the end of one speaker's utterance and the beginning of another speaker's utterance.

According to Frankel (1984), the much longer than normal pause (2.2 seconds) from the doctor, which follows a question framed as an optimistic statement, interrupts the 'preference for agreement' rule of conversations. So the location of the pause in the sequence of utterances allows the doctor to signal they are unable to endorse the patient's optimistic assessment. The patient's interpretation of the meaning of the interruption leads the patient to reverse their earlier statement into the more direct question format, 'It will?' which, in turn, allows the doctor to confirm the earlier negative assessment with: 'I'm afraid so' (Frankel, 1984). This small example shows the affinity between CA techniques and the poststructuralist approaches' preference for analyses of local, ephemeral situations where meaning is constituted moment by moment as an artefact of interaction. The development of audio and visual recording technologies have enabled highly detailed analysis of naturally occurring data, and CA research typically shares information about such things as the 
direction of a speaker's gaze and facial expressions in relation to their utterances are available for analysis.

\section{CA-based research into job interviews}

CA has been used most frequently to analyse conversations recorded for legal or other purposes, such as police interviews, court proceedings, or gatherings of public interest. There is relatively little research on employment interviews using CA or CA-influenced techniques, however. This is perhaps because employment interviews usually take place in confidential settings. Exceptions include the empirical investigations of the roles and outcomes of sameand cross-sex applicant-recruiter dyads by Graves and Powell $(1995,1996)$, and Linell and Thunqvist's (2003) analysis of simulated job interviews with young unemployed people. Gumperz, Jupp and Roberts (1979) used CA-oriented sociolinguistic techniques to analyse the features of communicative style that lead to negative or positive judgements of candidates for jobs. Roberts and Campbell (2005) and Campbell and Roberts (2007), in their research into job interviews with migrants to the UK, extend the work of Gumperz and his colleagues on these inferential processes by linking them to current organizational discourses around the job interview.

This relatively small body of previous research points up how little work has been done on naturally occurring data to explore how gender underlies the assumptions, structures and outcomes of employment interviewing. This is not to deny the wealth of research attention to employment interviews generally. There have been many research-based challenges to the employment interview's reliability, validity and usefulness in recruitment and selection for employment, as well as investigations of the role of the interview in applicants' decision-making about job offers. The popular literature is similarly replete with reviews, textbooks, popular books, articles and websites which describe and discuss roles and 
sequences in interview scripts, tell interviewers how to construct good-quality questions, and interviewees how to construct good-quality answers, and create favourable impressions via their attire, demeanour, and the documents associated with seeking employment: resumes, curricula vitae and cover letters. Employment interviews are pivotal points in most individuals' lives: they give entry to paid work and, potentially, employment security, advancement opportunities, dignity as productive members of society and specific standards of living. From an employer's perspective too, skills shortages have increased the difficulty of finding 'the right candidate for the job'. Employment interviews themselves are taking more time as candidates are interviewed intensively and often several times after the initial resumé check indicates acceptable knowledge, skills and abilities (Arthur, Inkson and Pringle, 1999; Cheney et al., 2004). Finally, in an era when legislation in many countries prohibits sex-based and other forms of discrimination, it is important to investigate how aspects of talk-in-interaction in the employment interview conversation may combine to unfairly, albeit unwittingly, discriminate against specific groups.

Revisiting a previous study: Campbell and Roberts, 2007

This section shows how the CA analysis of Campbell and Roberts (2007) who focused on intercultural issues leading to unfairness in their study of job interviews, also reveals gender issues in the interactions between interviewers and interviewees. Campbell and Roberts authors analysed 40 hours of recorded job interviews of 21 white British candidates, 21 British minority ethnic candidates, and 19 candidates who were born outside the UK and for whom English was not an expert language. The authors also held brief interviews with several candidates and gave video feedback to interviewers. They found the most common reasons for rejecting candidates related either to aspects of personality, for example, 'untrustworthiness'; or general assessments of skill deficiencies, for example 'poor communication skills'. Less frequently the interviewers referred to cultural stereotypes 
(Campbell and Roberts, 2007, p. 244) as a basis for not offering a candidate a position. The authors argue that these judgements, which adversely affected a significant proportion of candidates born abroad, were an artefact of candidates' talk. Specifically, unfavourable judgements arose from interviewers' perceptions that candidates produced 'jarring' juxtapositions of personal and institutional modes of speaking and identities, and that their talk showed an inadequate synthesis of personal and institutional discourses. Candidates could be judged unfavourably by producing rote-learned 'textbook' answers that used buzzwords but did not employ the candidates' own voice. However, candidates who were judged overly personal or informal in how they presented themselves, were also seen as 'unprofessional' (Campbell and Roberts, 2007 p. 244). The authors conclude that to be successful, interviewees must synthesize their talk at the micro-level of lexical, grammatical, rhetorical and interactional features with their talk at the macro-level of the underlying organizational ideologies - dedication to work, flexibility to meet the employer demands, customer service, and so on. This is a feat that the life-worlds of non-native English speakers born outside the UK are less likely to have equipped them to master.

Campbell and Roberts' study did not indicate that more women than men were unsuccessful in securing a job, and they gave examples of successful conversation strategies - those that successfully married institutional and personal discourses - that emanated from female candidates. Nevertheless, these authors' analysis of candidates' job interview talk and how interviewers judge it also recall the findings about language and gender derived from feminist linguistics research, and feminist findings about women's experience of work. We demonstrate this in the next section, where we summarize and present a short re-analysis of Campbell and Roberts' (2007) data under three headings which pertain equally to gender: the competence of impersonality, the competence of personal disclosure, and the claim to belong. 
Part of being competent at job interview talk means using institutional language rather than 'the here and now biographical talk of personal stories about the self' (Campbell and Roberts 2007, p. 248). Institutional language, according to Bourdieu (1991), is characterized by 'impartiality, symmetry, balance, propriety, decency and discretion', and by the creation of a certain professional distance between the people using it. Auer (1998) and MoralesLópez, Prego-Vásquez and Domínguez-Seco (2005) point out commonly occurring linguistic features of impartiality, including more analytic framing of talk (including giving lists of characteristics and argumentative modes of structuring speech); more employment of technical vocabulary and abstract formulations such as nominalizations and grammatical metaphors; reduced use of the personal pronoun particularly as a grammatical subject; and the use of certain types of modality, in which candidates evaluate their experience in terms of what they should believe and do, for example: 'it's important to be flexible', 'your work is more important than your social life.'

In the interviews analysed by Campbell and Roberts, candidates born outside the UK were assessed by the interviewer/s as having poorly synthesized personal and institutional discourses. An example is candidate Yohannes:

\section{Yohannes, Ethiopian, Unsuccessful}

1. I: an example where you been working as part of a team=

2. $\mathrm{C}:=\mathrm{mhm}$

3. I: to achieve something=

4. (twenty seconds of talk deleted)

5. C: and we were friendly we were not er:m bothering to argue this is your

6. your job is my job we are all together we had togetherness (.) they are very

7. helpful (.) they are a lot of integration each other e:r if something happen

8. we have to sort it out ourselves (.) instead of complaining to each other we

9. have to (.) know (.) the first thing whoever comes first mm say for example if

10. you have a job today interview and then he offer the job in that place we tell

11. that person if he doesn't understand he asks he can ask us five to six times

12. doesn't matter $=$

13. $\mathrm{I}:=\mathrm{mhm}$

14. C: er:m because he is new at least for one month he might get confused he 


\section{5. might}

16. I: what to do- has to do- okay ho- how many of you in th- in that team

17. C: e:r we were (.) me Mohammed about five people (3) that was in valet

18. service [and that was in

19. I: right okay]

20. C: was in public [area

21. I: how] many rooms would you be covering on a- any given date

22. C: er:m (.) one room we had we had guests laundry to bring it from the

23. floors

24. I: okay

25. C: then we have to wash them in e:r machine or if not we send them to 1- er

26. dry cleaning (1) and we have to do go and get that erm but th:e how much it

27. costs (5) and then we have to give them back to the customers (6)

Source: This and all subsequent natural language extracts are from Campbell and Roberts (2007).

In analysing this extract, Campbell and Roberts point out how Yohannes employs a personal style in lines 5-15 but fails to recognize the need to discuss teamworking in terms of its benefit to the organisation rather than his personal enjoyment. At line 17 he abandons this personal discourse in favour or an impersonal listing of tasks required of him. The interviewers considered this insufficiently personalized and evidence that Yohannes was unwilling to take responsibility. However, Yohannes' switch to a depersonalized style was not something he did unprompted; it was in response to a cue from the interviewer at line 16, who returned the conversation to a formal register and a low, almost banal, level of questioning. Yohannes, in following this cue from the interviewer, obeyed the 'rules' of the job interview, but the consequence of doing so was to make his responses appear rather dull and lacking in initiative. Similarly, candidate Alison, who was being interviewed for a hospital receptionist's position, was criticized by the interviewers for framing her response to a question about security about medical records in a personalized, non-technical way:

$\mathrm{C}:[\ldots]$ they're coming in here and hoping that their medical records . . . are as safe as they possibly could be. 
She spoke in terms of empathy with patients' affectivity and vulnerability, failing to explicitly use the language and categories of customer service and data protection legislation to frame her response. This was seen as 'unprofessional' (Campbell and Roberts, 2007, p. 252).

These features of Yohannes' and Alison's speech which cost them the job, are also consistent with so-called 'women's language'. The linguistic features of impartiality required in the two job interviews just discussed, are at odds with the language of 'women's linguistic culture' as discussed in 'difference' perspectives. Analytical, abstract and argumentative talk go against female linguistic culture which stresses empathy and comfort rather than analytical approaches to problems (Tannen, 1996). Difference perspectives on language and gender suggest that for women to demonstrate the institutional competence of impersonality, discretion and distance, means they are required to bridge a greater cultural gap than men. A post-structuralist perspective reveals the same problem. The interviewer's power means they can use the 'rules' of the job interview to 'cue' female candidates - who recognize and obey the rules - into responding in ways the interviewer has already judged to be unprofessional.

\section{The competence of personal disclosure}

As well as demonstrating the competence of impersonality, Campbell and Roberts (2007) found that candidates need to show its apparent opposite: a competence of personal disclosure which reveals them to be well rounded individuals who are aligned at a personal level with the values and preferred behaviours of the organization. The competence of personal disclosure includes being able to relate narratives concerning the self, for example, describing interpersonal interactions with difficult workmates indicates the candidate is not bothered by this, and regards it simply as a 'challenge'. The euphemism 'challenge' reframes 
something that is normally unpleasant and frustrating as interesting and even enjoyable.

Personal disclosure also requires candidates to give vivid accounts of their motivations and values in a way which shows them to be oriented to the organisation's needs. In successful candidates these features would be delivered in a 'high-involvement' conversational style: using colloquial vocabulary and idiosyncratic language, popular sayings and direct speech quotations. The interviewer indicates approval of the candidate's personal disclosure by echoing the candidate's micro-level behaviours, rather than ignoring, correcting, or translating them. This is shown in the following extract:

\section{Pippa, White British, Successful}

1. C: erm well it is I think t-m-majority of the jobs that I have worked in I

2. have been erm customer focussed and deadlines and under pressure (.)

3. hhh erm catering I've m-you know

4. I1: $\mathrm{mmm}$

5. C: my family own a business and I've worked in that since the age of nine (.)

6. you know helping them out (.) erm but that that's I suppose that's a

7. different field altogether from $=$

8. I1: =yeah

9. C: customer focus but (1) I've sort of gone off on a tangent now.hhh (3)

10. I1: nno it's (1) I mean the range of experience just [shows you

11. C: $\mathrm{mmm}]$

12. I1: in many ways that you're used to $=$

13. $\mathrm{C}:$ =yeah I'm quite

14. I1: having new things thrown at you so (.) no I-I don't see anything (.) (to

15. I2) anything you need to add to that (xxxxxxx)?

16. I2: no I'm comfortable with that

In lines 1-9 Pippa discusses her personal history in her family business to inject the required element of personalization and demonstrate her understanding of organizational demands. The interviewers respond here and elsewhere with a high level of back channelling, overlap and positive appraisal, giving the interaction a conversational mood (Campbell and Roberts, 2007 p. 255). They allow additions, digressions and questions about their personal views, 
thereby establishing affiliative alliances rather than cutting the interviewee off, as they did with Yohannes. Instead of switching into formal language and low-level questioning as they did in Yohannes' interview, the interviewer completes Pippa's sentence at line 14 using Pippa's colloquial language. This helps her: endorsing and summarizes her argument about the value of her previous experience.

Pippa, a woman, was successful. However feminist research, and specifically constructionist approaches to gender and language, indicate a gender aspect in the 'work as identity-forming' competence of personal disclosure. Just as candidates born outside the UK doing low-paid work typically do not use their work to form their identity (Campbell and Roberts 2007), women whose jobs are often subject to day-to-day and even year-by-year interruptions for domestic, childcare and eldercare reasons, are unlikely to speak about their work as identity-forming. For both groups - people from outside the country in which they are seeking a job, and women with family responsibilities - there is a wider gulf between the discourses they generally use to talk about themselves, and those they can readily use to indicate the value of their experience to the organisation.

\section{The claim to belong}

Demonstrating mastery of impersonal and the personal discourses of the job interview reinforces a candidate's implicit claim to 'belong' to the organizational world of the interviewer. The copious literature on 'organizational fit' (including this volume) suggests that the demonstration of belonging is also an independent competence. The personalization discourse typically requires a confessional approach, where the candidate admits to weaknesses. The amount of space devoted to the 'tell me about your weaknesses' question in the popular job interview advice literature shows the question's importance in the personal disclosure competence of job interview language. The skill required is difficult and delicate: 
to use personal language to demonstrate awareness of one's deficiencies or foibles and how they are likely to be viewed in the organization, and yet to manage this to one's advantage. It is easy to get it wrong, particularly if the 'weakness' is a fundamental aspect of the person or their identity. Sara is a case in point:

\section{Sara, Maltese, Unsuccessful}

1. I: $\{$ [looking down] how- how do you ensure (.) you know wh- when you're a

2. manager that you (.) you learn from $\}\{[\mathrm{I}$ looks at $\mathrm{C}]$ experience and you pick

3. up particular lessons from past mistakes\} \{[I looks down, begins writing] (1)

4. (twenty five seconds of talk deleted)

5. C: I mean I'm Maltese $\{[\mathrm{C}$ moves arms $]$ I tend to talk with my hands $\}$ and one

6. thing that's really brought up quite often when I'm talking in a meeting you

7. know I'm sitting there with my $]\}\{[C$ gesticulates with hands, I looks up and

8. nods] hands flailing away like this \} [[Ilooks down] which puts everybody off

9. because they're looking at you know \{[I looks up, $\mathrm{C}$ moves arms] what on

10. earth is she doing $\}$ [[I looks down] doing this [business

11. I: right]

12. C: so I've made a conscious effort to keep my hands in my lap [ I mean

13. I: i-]

14. C: that that is one [thing that somebody told me

15. I: how do you er:m]\} \{[I looks up] (.) how do you ensure though if you

16. (choose) somebody in your team that maybe they they maybe don't want to be

17. too critical you know they're only really sort of being positive or being nice

18. for the sake of it really is that not a danger some times

19. C: that is a danger but-

20. I: they might not want to say that actually you was pretty- you were just

21. mumbling it was pretty awful but I daren't say that because she's the boss

22. (fifteen seconds of talk deleted)

23. I: so can you give me some examples of things you've picked up then from

24. using that

25. C: well I just did that that was the one that comes [to mind

26. I: the one about] are there any other sort of things that

27. C: er:m-

28. I: apart from you know your own sort of body language and things which (.)

29. you know I think from presentations we always there's always things to pick

30. up there

31. C: $\mathrm{mm}$

32. I: sort of ex- examples maybe s- substan- in terms of- 
Campbell and Roberts (2007, p. 263) point out that Sara described a genuine individual foible, her 'Maltese' tendency to 'talk with her hands' (line 5). While Campbell and Roberts do not make this point, it is worth noting that this was a more honest response than invoking homogenized personal characteristics such as 'time-management issues', which may be easier to reframe as correctible or even strengths in disguise. Sara's highly personal, narrativized and satirical acting out of her 'Maltese' behaviour and the possible reaction of her colleagues to it shows her reflexive awareness of self, which ought to be an advantage in a job interview. However it breaks the rules of the job interview game, whose 'rules' are determined by the interviewer. The interviewer disqualified it as an appropriate example (line 28), viewing it as 'indiscreet', and explicitly linking it to Sara's ethnic identity: "I know she's Maltese, but..." (Campbell and Roberts, 2007, p. 263). The effect of the interviewer's judgement is to construct Sara as an outsider to both the organizational and the national culture.

It is possible to analyse the same incident from a gender perspective. Both essentialist and constructionist perspectives on gender and language point to highly personalized, intimate, narrativized talk which incorporates emphatic body language as characteristic of female speech (Hirschman, 1973). So referring to this personal foible overtly is likely to attention to the speaker's gender as well as her ethnicity. Moreover for women, who more typically seek and offer empathy rather than strategize solutions to problems, the need in the job interview to strategize personal weaknesses imposes a male institutional norm. Gender, as well as ethnicity, can operate in institutional discourses to discriminate between organizational members and non-members, as "language serves to confirm and consolidate the organizations which shape it" (Fowler et al., 1979). Institutional discourses are used more frequently, interviewer language becomes more depersonalized, and requirements for relevancy and 'appropriate' discourse use (as defined by the interviewer) become stricter 
when rejecting those who are constructed as not belonging (Bourdieu, 1991; Roberts and Campbell, 2005; 2006).

\section{Implications}

So far, naturally occurring employment interviews seem to have remained relatively inaccessible - or at least infrequently accessed - as sites for empirical research into gender and language. Nevertheless, this brief re-examination of data from a study of employment interviews in intercultural settings has implications for future interviewees and interviewers. First, CA analysis of interviews heightens our recognition of the interview as a performance. This is in many ways already obvious from the wealth of advice to candidates, especially women, about clothing, demeanour, hair, make-up, and so on. The need to adjust one's costume to fit the show foreshadows the insights from CA that the art of the interview is to predict and then artfully match one's linguistic self-presentation at micro- and macro-levels to the discourses of the organization one expects to join. Candidates may consider challenging interview norms, but the speed and subtlety of interview interactions, and the unequality of the interviewer-candidate power relationship makes this risky and difficult.

Second, our gender-oriented re-analysis of Campbell and Roberts (2007) suggests that the competences involved in managing job interview languages are likely to present more hazards for women, first because the required linguistic strategies conflict with elements of women's linguistic culture and, second, because the dominant discourse that work is more important than one's outside commitments is more sustainable for men than for women. These results signal that interviewees and interviewers alike need to continue to maintain and improve their awareness of the discourses that predominate at work, and continue to question them. 
Finally, the re-analysis reinforces Eckert and McConnell-Ginet's observation (2003, p. 304) that "the claims people make with language $[\ldots]$ are claims about who they are." But, contrary to appearances, the interviewer is not purely a passive audience or recipient of the interviewee's claims; CA shows how interviewers impose their own judgements and claims, however unwittingly, about who the interviewee is in their moment-by-moment co-creation of the interview conversation. Interviewers, however, are alone in assessing interviewees' success at the interview, despite their contribution to constructing the performance.

\section{Ways forward}

Exposing how the linguistic norms of interviews tend to create unfair outcomes prompts questions about what should be done to rectify the situation. The options for interviewees to do this are limited because of their less powerful position in the job interview context. Regular interview practice appears to be a good option, especially if candidates are informed about the framing of responses that goes on in interviews. Doing this kind of practice is not easy, however, especially if one is inexperienced with interviews, as young people and women who have been outside the paid workforce for a long time are likely to be. Linell and Thunqvist (2003) found it was difficult for young people to maintain the framing needed to practise employment interviews. Buzzanell (2000) advocates a new, 'powersharing' approach to employment interviewing but this is not yet mainstream practice.

The fact that the power balance in job interviews lies with the interviewer suggests that changing interviewer awareness and practice has much to offer. Training in interview techniques, particularly from an equal opportunities perspective, is now common in large organizations. However some current training in interviewer questioning techniques, such as how to 'drill down' to the 'truth' of what a candidate is saying using deductive questioning techniques (see Roberts, 2013, for a description) actually contributes to the problem. 
Interviewers are also often constrained by the need to be accountable for interview results, which often requires them to write notes during the interview (see Roberts and Campbell, 2005). This tends to make interviewers keen to ensure interviews are easily processable - and leads them to push candidates into modes of talking which are easy for interviewers to take notes about. They are likely to punish candidates who cannot produce these modes by changing the line of questioning, hyper-clarifying, removing eye contact and so on during the interview, or by assessing them as poor communicators afterwards. Interviewer training should be changed and expanded to make interviewers aware of how the interview as a whole, and their linguistic behaviours in particular, can help - but also actively disadvantage - specific candidate groups, including women. Alternative behaviours are possible, such as allowing candidates to tell their stories in their own way and in their own time. If interviewers are aware of how they may unfairly construct specific ways of speaking as indicative of organizational 'belonging' or otherwise, they are more likely to suspend such judgements. This is not a radical shift, but rather an extension of good practice in ensuring interview questions are relevant to the job.

\section{Conclusion}

In Verbal Hygiene, Deborah Cameron voices her concern about how “ideas about language are recruited to non-linguistic concerns" and the importance of "exposing [...] unspoken assumptions [about language] to critical scrutiny" (Cameron, 1995, p. 11). The aim is to "challenge verbal hygiene practices we find objectionable, defend those we find value in, and know which is which" (Cameron, 1995, p. 10). In our re-analysis of Campbell and Roberts' (2007) data, we mobilized these authors' use of linguistic interactional analysis to challenge gender-based, unspoken assumptions about the unspoken elements of job interview language. This language context is crucial because job interviews are still the primary way that women and men get in to organizations. We also pointed to some practical ways these 
unspoken assumptions can be made explicit, revealing their dubious foundations. Much more work of the same kind is possible and necessary; we invite other researchers to join in to the benefit of organizations and their would-be members.

\section{References}

Arthur, M.B., K. Inkson and J.K. Pringle (1999), The New Careers: Individual Action and Economic Change, London: Sage.

Auer, P. (1998), 'Learning How to Play the Game: An Investigation of Role-played Job Interviews in East Germany', Text 18, 17-38.

Baxter, J. (2006), 'Putting Gender in its Place: A Case Study on Constructing Speaker Identities in a Management Meeting', in M.A. Barrett and M.J. Davidson Gender and Communication at Work, Aldershot: Ashgate, pp. 154-65.

Bohan, J.S. (1993), 'Regarding Gender: Essentialism, Constructionism and Feminist Psychology', Psychology of Women Quarterly 17, 5-21.

Bourdieu, P. (1991), Outline of a Theory of Practice (trans. R. Nice), Cambridge: CUP.

Bucholtz, M., A.C. Liang, and L. A. Sutton (eds) (1999), Reinventing Identities: The Gendered Self in Discourse, Oxford: OUP.

Butler, J. (1990), 'Performative Acts and Gender Constitution: An Essay in Phenomenology and Feminist Theory', in S. Case (ed.) Performing Feminisms. Baltimore, MD: Johns Hopkins University Press.

Buzzanell, P.M. (2000), 'The promise and practice of the new career and social contract: Illusions exposed and suggestions for reform', in P.M. Buzzanell (ed.), Rethinking 
Organizational and Managerial Communication from Feminist Perspectives, Thousand Oaks, CA: Sage, pp. 209-35.

Cameron, D. (1995), Verbal Hygiene, London: Routledge.

Cameron, D. (1998), 'Gender, Language and Discourse: A Review Essay', Signs 23 (4), 94573.

Campbell, S. and C. Roberts, (2007), 'Migration, ethnicity and competing discourses in the job interview: Synthesizing the institutional and the personal', Discourse \& Society 18 (3), $243-71$.

Cheney, G., L. Christensen, T. Zorn and S. Ganesh (2004), Organizational Communication in an Age of Globalization: Issues, Reflections, Practices, Prospect Heights, IL: Waveland.

Coates, J. (1993), Women, Men and Language, Harlow: Longman.

Conrick, M. (1999), Womanspeak, Dublin: Marino Books.

Crawford, M. (1995), Talking Difference: On Gender and Language, London: Sage.

Eckert, P. and S. McConnell-Ginet, (2003), Language and Gender, Cambridge: CUP.

Foucault, M. (1972), The Archeology of Knowledge, London: Routledge.

Fowler, R., B. Hodge, G. Kress, and T. Trew, (1979), Language and Control, London: Routledge.

Frankel, R.M. (1984), 'From sentence to sequence: Understanding the medical encounter through microinteractional analysis', Discourse Process, 7, 135-70.

Goddard, A. and L.M. Patterson (2000), Language and Gender, London: Routledge. 
Graves, L.M. and G.N. Powell (1995), 'The effect of sex similarity on recruiters' interview and recruiters' evaluation of actual applicants', Journal of Occupational and Organizational Psychology, 48, 85-98.

Graves, L.M. and G.N. Powell (1996), 'Sex similarity, quality of the employment interview and recruiters' evaluation of actual applicants', Journal of Occupational and Organizational Psychology, 69, 243-61.

Gray, J. (1992), Men are from Mars, women are from Venus: How to get what you want in your relationships, London: Harper Collins.

Gumperz, J., T.C. Jupp, and C. Roberts (1979), Cross-talk: A Study of Cross-cultural Communication [A film and notes], London: BBC/National Centre for Industrial Language Training.

Hare-Mustin, R.T. and J. Maracek, (1994), Making a Difference: Psychology and the Construction of Gender, New Haven, CT: Yale University Press.

Hirschman, L. (1973), Female-male differences in conversational interaction. Paper presented at Linguistic Society of America, San Diego.

Hollway, W. (1994), 'Beyond Sex Difference: A Project for Feminist Psychology’, Feminism \& Psychology, 4 (4), 538-46.

Holmes, J. (1995), Women, Men and Politeness, Harlow: Longman.

Kitzinger, C. (2000), 'Doing Feminist Conversation Analysis', Feminism \& Psychology, 10 (2), 163-93.

Lakoff, R. (1973), 'Language and Woman's Place', Language in Society, 2, 45-79. 
Linell, P. and D. Thunqvist, (2003), 'Moving In and Out of Framings: Activity Contexts in Talks With Young Unemployed People Within a Training Project', Journal of Pragmatics, 35, 409-34.

Lyotard, J.F. (1984), The Postmodern Condition: A Report on Knowledge, Minneapolis: University of Minnesota Press.

Mapstone, E. (1998), War of Words: Women and Men Arguing, London: Chatto and Windus. Morales-López, E., G. Prego-Vásquez and L. Domínguez-Seco (2005), 'Interviews Between Employees and Customers During a Company Restructuring Process', Discourse \& Society $16(2), 225-68$.

Pauwels, A. (1998), Women Changing Language. New York: Addison Wesley Longman.

Roberts, C. (2013), 'The Gate-Keeping of Babel: Job Interviews and the Linguistic Penalty', in A. Duchene, M. Moyer and C. Roberts (eds), Language, Migration and Social Inequalities: A Critical Sociolinguistic Perspective on Institutions and Work, Bristol: Multilingual Matters, pp. 82-94.

Roberts, C. and S. Campbell (2005), 'Fitting Stories into Boxes: Rhetorical and Textual Constraints on Candidates' Performances in British Job Interviews', Journal of Applied Linguistics, 2 (1), 45-73.

Sacks, H. (1984), 'Notes on Methodology', in J.M. Atkinson and J. Heritage (eds), Structures of Social Action: Studies in Conversation Analysis, Cambridge: Cambridge University Press, pp. 21-27. 
Schegloff, E.A. (1991), 'Reflections on Talk and Social Structure', in D. Boden and D.H.

Zimmerman (eds), Talk \& Social Structure, Berkeley: University of California Press, pp. 4470.

Schegloff, E.A. (1997), ‘Whose Text, Whose Context?’ Discourse \& Society 8 (2), 165-87.

Speer, S. (2005), Gender Talk: Feminism, Discourse and Conversation Analysis, London:

Routledge.

Spender, D. (1980), Man Made Language, Boston: Routledge and Kegan Paul.

Stokoe, E.H. (2000), Towards a Conversation Analytic Approach to Gender and Discourse, Feminism \& Psychology, 10: 590-601.

Tannen, D. (1990), You Just Don't Understand: Women and Men in Conversation, New York: William Morrow.

Tannen, D. (1994), Talking from 9 to 5: Women and Men at Work, New York: Avon.

Tannen, D. (1996), Gender and Discourse, New York: OUP.

Tannen, D. (1999), 'The Display of (Gendered) Identities in Talk at Work', in M. Bucholtz, A.C. Liang and L.A. Sutton (eds), Reinventing Identities: The Gendered Self in Discourse, Oxford: OUP, pp. 221-40.

ten Have, P. (2007), Doing Conversation Analysis, $2^{\text {nd }}$ ed., London: Sage.

West, C. and S. Fenstermaker (1993), 'Power, Inequality and the Accomplishment of Gender: An Ethnomethodological View', in P. England (ed.) Theory on Gender/Feminism on Theory, New York: Aldine de Gruyter, pp. 151-74.

Wodak, R. (ed.) (1997), Gender and Discourse, London: Sage. 
Zimmerman, D.H. and C. West (1975), 'Sex Roles, Interruptions and Silences in Conversation', in B. Thorne and N. Henley (eds), Language and Sex: Difference and Dominance, Rowley, MA: Newbury House. 